\title{
Morfologia e propriedades físicas de solo segundo sistemas de manejo em culturas anuais
}

\author{
Rafael Fuentes-Llanillo ${ }^{1}$, Maria de F. Guimarães ${ }^{2}$ \& João Tavares Filho ${ }^{2}$
}

\begin{abstract}
RESUMO
Qualidade física do solo é sua capacidade de sustentar o pleno desenvolvimento das plantas. O objetivo deste trabalho foi estudar diferentes sistemas de semeadura direta para a produção de grãos em áreas de agricultura familiar sob Latossolo Vermelho no norte do Paraná, Brasil, através do estudo da morfologia e de algumas propriedades físicas do solo. O estudo foi baseado na descrição da estrutura de solo de perfis culturais em áreas cultivadas com lavouras anuais sob diferentes sistemas de manejo de solo (semeadura direta com e sem rotação de culturas, semeadura direta com escarificação eventual e o cultivo mínimo). Concomitantemente à descrição dos perfis foi determinada a resistência do solo a penetração, a densidade do solo, a umidade do solo e o grau de floculação da argila. Cada manejo estudado foi caracterizado por um tipo de estrutura de solo a qualse correlacionou com os valores de resistência, densidade e grau de floculação e em todos os manejos estudados abaixo dos 0,30 m, os perfis analisados apresentavam condições estruturais satisfatórias ao desenvolvimento radicular.
\end{abstract}

Palavras-chave: sustentabilidade, plantio direto, perfil cultural, densidade do solo, resistência a penetração

\section{Morphology and physical properties of soil according to tillage systems in annual crops}

\begin{abstract}
Soil physical quality is the ability to sustain the full development of plants. The aim of this research was to study different tillage systems for grain production in family farming enterprises on an Oxisol in northern Parana, Brazil, through the study of morphology and physical properties of soil. The study was based on description of soil structure of soil profiles in cultivated areas with annual crops under different soil management systems (no-tillage with and without crop rotation, no-tillage with eventual chisel ploughing and minimum tillage). Simultaneously with the profiles' description some physical properties were determined such as resistance to penetration, bulk density, soil moisture and the degree of clay flocculation. Each studied soil tillage system was characterized by a type of soil structure and correlated with values of resistance to penetration, density and degree of flocculation, and for all studied profiles below $0.30 \mathrm{~m}$ of depth the soil had good structural conditions for root development.
\end{abstract}

Key words: sustainability, no-tillage, cropping profile, bulk density, resistance to penetration 


\section{INTRODUÇÃO}

Entende-se por qualidade física do solo a capacidade do mesmo em sustentar o pleno desenvolvimento das plantas (Reichert et al., 2003). O uso de indicadores facilmente mensuráveis e que podem ser largamente reproduzidos é de suma importância no monitoramento da sustentabilidade.

Osistema de plantio direto de culturas anuais ocupa cerca de 5 milhões de hectares no Paraná e mais de 30 milhões de hectares no Brasil (Bernoux et al., 2006) e tem sido avaliado como sustentável devido aos seus efeitos positivos na conservação de solos, na construção integrada da fertilidade do solo sob aspectos químicos, físicos e biológicos, na redução de custos em combustíveis e manutenção de máquinas, na menor demanda de trabalho e na melhoria da rentabilidade das explorações (McGarry, 2003; Bolliger et al., 2006; Hobbs, 2007). Por outro lado, alguns efeitos negativos podem advir, dependendo das condições de adoção do sistema, como maior dependência de agroquímicos, principalmente de herbicidas (Bolliger et al., 2006) assim como a formação de camadas compactadas por efeito do tráfego pouco controlado de máquinas sobre o solo sem revolvimento (McGarry, 2003).

Os Latossolos Vermelhos muito argilosos provenientes de basalto, presentes no estado do Paraná, estão entre os mais ricos e mais produtivos solos do Brasil (Tavares Filho \& Tessier, 1998). Após a incorporação desses solos ao sistema produtivo problemas de degradação física, sobretudo alterações estruturais e compactação do solo, têm sido observados (Assouline et al., 1997; Tavares Filho et al., 1999, 2001; Giarola et al., 2007; Tavares Filho \&Tassier, 2009, Tavares Filho \& Tessier, 2010) e embora esses problemas possam existir desde o início da agricultura, sua extensão e seu impacto são considerados, hoje, de extrema intensidade (Lal \& Stewart, 1990). Portanto, o diagnóstico qualitativo de diferentes estruturas a campo, complementado pelas análises laboratoriais, pode ajudar na tomada de decisão quanto ao tipo de manejo a ser empregado no solo para manutenção ou melhoria da produtividade (Tavares Filho \&Tassier, 2009; 2010).

A análise da morfologia dos solos permite a caracterização dos horizontes antropizados (diagnóstico qualitativo do estado físico do solo) e pode ser feita, por exemplo,pelo método do perfil cultural que analisa, conjuntamente e visualmente,o efeito do manejo na estrutura do solo e desta no sistema radicular (Tavares Filho et al., 1999; Neves et al., 2003; Pereira Neto et al., 2007) e pela avaliação visual da estrutura do solo (Ball \& Douglas, 2003; Ball et al., 2007; Giarola et al., 2010). Esses métodos, associados com alguns indicadores de qualidade física dos solos, permitem ser replicados nas mais diversas situações dando boas indicações sobre o nível de sustentabilidade do sistema de manejo de solo em uso.

Considerando a existência de diferentes modalidades de semeadura direta para uma mesma região e solo, deverá haver diferenças na estrutura e propriedades físicas do solo. Desta forma, o objetivo deste trabalho foi estudar diferentes sistemas de semeadura direta para produção de grãos em áreas de agricultura familiar sob Latossolo Vermelho no Norte do Paraná, através do estudo da morfologia e de algumas propriedades físicas do solo.

\section{Material e Métodos}

As propriedades agrícolas (total de quatro) selecionadas para este estudo se caracterizam por apresentar produção mecanizada de grãos (Tabela 1) principalmente de soja e se localizam no estado do Paraná, entre as coordenadas $50^{\circ} 10^{\prime}$ e $51^{\circ} 30^{\prime} \mathrm{W}$ no Baixo Rio Tibagi e $22^{\circ} 40^{\prime}$ e $23^{\circ} 30^{\prime} \mathrm{N}$ entre o Rio Paranapanema e o Trópico de Capricórnio, cuja cidadepolo é Londrina. As altitudes variam entre 350 e $700 \mathrm{~m}$ sobre o nível do mar e o solo predominante nas parcelas é o Latossolo Vermelho Distroférrico (Typic Haplorthox) cujos teores de argila variam de 550 a $700 \mathrm{~g} \mathrm{~kg}^{-1}$ para a profundidade $0-60 \mathrm{~cm}$. A precipitação pluviométrica média na região varia de 1350 al $650 \mathrm{~mm}$ anuais (Fuentes-Llanillo et al., 2006a).

$\mathrm{O}$ estudo baseou-se, inicialmente, em uma descrição dos perfis de solo cultivado com culturas anuais em diferentes manejos (CASDR, CASDE, CASD e CAPM - (Tabela 1) a partir do método do perfil cultural,segundo Tavares Filho et al. (1999) que buscam descrever a organização estrutural dos torrões com especial atenção para existência de impedimentos físicos ao desenvolvimento das raízes das culturas. Foram avaliados doisperfis (medindo 1,5 x 0,6 x 0,8 $\mathrm{m}$ ) por propriedade transversal às linhas de cultivo, fora da ação do rodado das máquinas agrícolas, entre os dias 8 e 30 de novembro de

Tabela 1. Características de uso e manejo do solo das propriedades agrícolas usadas neste estudo e produção média de soja durante o tempo de 6 anos

\begin{tabular}{|c|c|c|}
\hline Uso e manejo do solo & Características gerais & $\begin{array}{c}\text { Produção média } \\
\text { (de } 6 \text { anos) de soja (kg ha }{ }^{-1} \text { ) }\end{array}$ \\
\hline CASDR & $\begin{array}{l}\text { Culturas anuais em semeadura direta e rotação de culturas (verão: soja, milho a cada três } \\
\text { anos; inverno: trigo, milho safrinha, aveia branca, aveia preta, triticale). Uso intensivo de } \\
\text { insumos. Uso de terraço agrícola. }\end{array}$ & 3398 \\
\hline CASDE & $\begin{array}{l}\text { Culturas anuais (soja, milho safrinha) em semeadura direta sem rotação de culturas. } \\
\text { Escarificação de } 4 \text { em } 4 \text { anos até } 25-30 \mathrm{~cm} \text {, com rolo destorroador. Uso intensivo de } \\
\text { insumos. Uso de terraço agrícola. }\end{array}$ & 3390 \\
\hline CASD & $\begin{array}{l}\text { Culturas anuais (soja, milho safrinha) em semeadura direta sem rotação de culturas e sem } \\
\text { escarificação. Uso de semeadeiras alugadas com consequente obtenção de produtividades } \\
\text { mais modestas devido à realização da semeadura fora dos momentos ótimos e com qualidade } \\
\text { discutível. Uso intensivo de insumos. Uso de terraço agrícola. }\end{array}$ & 2624 \\
\hline CAPM & $\begin{array}{l}\text { Culturas anuais (soja, milho safrinha) com preparo mínimo do solo até } 25-30 \mathrm{~cm} \text {, sem } \\
\text { rotação de culturas. As semeaduras são realizadas com máquinas de semeadura direta } \\
\text { independente do nível de revolvimento feito pelas operações de preparo (uma escarificação e } \\
\text { uma gradagem leve). Uso de terraço agrícola. }\end{array}$ & 3099 \\
\hline
\end{tabular}


2006. Nesse período as lavouras de verão estavam em vias de implantação ou recém implantadas.

As unidades morfologicamente homogêneas do perfil foram descritas de acordo com a seguinte nomenclatura (Tavares Filho et al., 1999):- A) para os modos de organização dos torrões: 1) "L" - estrutura livre (estrutura composta por torrões sem adesão entre si e terra fina, porosidade entre torrões elevada); 2) " $\mathrm{F"} \mathrm{-}$ estrutura com fissuras(estrutura fragmentada (torrões separados por fissuras nítidas), porosidade preferencial entre torrões) e 3) "C" - estrutura contínua (estrutura composta por torrões bem unidos (aderidos) entre si aparentemente sem porosidade entre torrões); - B) Para a descrição interna dos torrões: 1) $\mu$ estado interno microagregado, forte porosidade, 2) $\Delta$ - torrões compactos (torrões poliédricos angulares (arestas angulares com faces planas e lisas), compactos, porosidade intra-agregados) e de transição entre torrões porosos e compactos: $\mu \Delta$ - torrões mais porosos que compactos ou $\Delta \mu$ - torrões mais compactos que porosos.

Concomitante à descrição dos perfis foi determinada a resistência do solo à penetração, com penetrógrafo de mola, cone e haste padrão ASAE, marca Soil Control modelo Penetrographer SC-60, com diâmetro da base do cone de 12,8 mm e ângulo de $30^{\circ}$, além de registro contínuo da pressão em $\mathrm{MPa}$. As determinações foram no entorno de cada trincheira, com doze repetições no rodado (seis de cada lado da trincheira) e doze repetições fora do rodado (seis de cada lado da trincheira) até a profundidade de $45 \mathrm{~cm}$ com leitura de $5 \mathrm{em} 5 \mathrm{~cm}$.

Foram determinados, também, a densidade do solo pelo método do anel volumétrico $\left(98 \mathrm{~cm}^{3}\right)$, a umidade do solo durante a realização da análise do perfil e por ocasião da determinação da resistência do solo e o grau de floculação da argila (GF) pela fórmula $\mathrm{GF}=($ argila total - argila dispersa em água $) /$ argila total, sendo as amostras de solo analisadas pelo método da pipeta (EMBRAPA, 1997). Para cada determinação foram feitas 6 repetições e determinado o erro padrão da média.

\section{Resultados E Discussão}

A descrição da organização estrutural dos perfis de solo feita a campo sob diferentes manejos de cultura anual, é apresentada nas Tabelas 2 a 5 .

As descrições apresentadas se assemelham às descrições de perfis feitas por Tavares Filho \& Tessier (1999); Neves et al. (2003); Benito et al. (2008); Tavares Filho \& Tessier (2009) em solo semelhante, sob os mesmos manejos e permitiram concluir que o manejo CASDR, com boa cobertura e rotação de culturas, apresentou o perfil de solo com melhor morfologia estrutural, sem ocorrência de compactação visível e medida (Ds média variou de 1,20 (entre 0 e $8 \mathrm{~cm}$ ) a 1,25 (entre 8 e $50 \mathrm{~cm}$ ) $\mathrm{Mg} \mathrm{m}^{-3}$ ), com traços de atividade biológica e aparentemente boa porosidade;já no manejo CASD verifica-se aumento da densidade do solo (Ds variou de 1,30 (entre 0 e $23 \mathrm{~cm}$ ) a 1,26 (entre 23 e $50 \mathrm{~cm}$ ) $\mathrm{Mg} \mathrm{m}^{-3}$ ) em virtude, provavelmente, do tráfego de máquina sobre a superfície do terrenoem condições inadequadas de umidade (semeadoras alugadas) e a menor cobertura do solo. Nessas condições a probabilidade de degradação do solo aumenta devido à presença de estruturas mais compactas $(\mathrm{C} \Delta \mu)$, consequência da acomodação das
Tabela 2. Perfis de solos sob cultura anual com semeadura direta e rotação de culturas (CASDR)

\begin{tabular}{|c|c|}
\hline $\begin{array}{c}\text { Modo de } \\
\text { organização }\end{array}$ & Descrição feita a campo \\
\hline & Estrutura "livre" composta por torrões poliédricos \\
\hline $\begin{array}{c}L \mu \\
(0-8 \mathrm{~cm})\end{array}$ & $\begin{array}{l}\text { sem adesão entre si e terra fina, porosidade entre e } \\
\text { intra-agregados visível, desenvolvimento de raízes } \\
\text { em todas as direções. Ds }=1,20( \pm 0,02) \mathrm{Mg} \mathrm{m}^{-3} \text {; } \\
\text { Argila }=600 \mathrm{~g} \mathrm{~kg}^{-1}\end{array}$ \\
\hline $\begin{array}{c}\mathrm{C \mu} \\
(8-50 \mathrm{~cm})\end{array}$ & $\begin{array}{l}\text { Estrutura "contínua" composta por torrões } \\
\text { poliédricos subangulares (arestas arredondadas e } \\
\text { faces planas), bem unidos (bem aderidos entre si), } \\
\text { aparentemente sem porosidade entre torrões, mas } \\
\text { com porosidade intra-agregados. Presença de raízes } \\
\text { distribuídas em todas as direções (horizontal e } \\
\text { vertical) e de porosidade biológica (macro poros bem } \\
\text { arredondados). Ds }=1,25( \pm 0,05) \mathrm{Mg} \mathrm{m}^{-3} \text {; Argila } \\
=720 \mathrm{~g} \mathrm{~kg}^{-1}\end{array}$ \\
\hline OBS: & $\begin{array}{l}\text { - aparentemente esse manejo com rotação de } \\
\text { culturas propiciou, no solo, um ambiente propício ao } \\
\text { desenvolvimento radicular e à atividade biológica }\end{array}$ \\
\hline
\end{tabular}

Tabela 3. Perfis de solos sob cultura anual com semeadura direta sem rotação de culturas (CASD)

\begin{tabular}{|c|c|}
\hline $\begin{array}{c}\text { Modo de } \\
\text { organização }\end{array}$ & Descrição feita a campo \\
\hline $\begin{array}{c}\mathrm{C} \Delta \mu_{\Delta \mu} \\
(0-23 \mathrm{~cm})\end{array}$ & $\begin{array}{l}\text { Estrutura "contínua" composta por torrões } \\
\text { predominantemente poliédricos angulares (arestas } \\
\text { angulares e faces planas e lisas), bem unidos (bem } \\
\text { aderidos entre si), embora ainda tenha sido possível } \\
\text { visualizar presença de torrões com aspecto poroso, } \\
\text { aparentemente sem porosidade entre torrões e com } \\
\text { porosidade intra-agregados pequena. Presença de } \\
\text { rázes estas preferencialmente horizontais. Ds }=1,30 \\
( \pm 0,05) \mathrm{Mg} \mathrm{m}^{-3} ; \text { Argila }=600 \mathrm{~g} \mathrm{~kg}^{-1}\end{array}$ \\
\hline $\begin{array}{c}\mathrm{C} \mu \\
(23-50 \mathrm{~cm})\end{array}$ & $\begin{array}{l}\text { Estrutura "contínua" composta por torrões } \\
\text { poliédricos subangulares (arestas arredondadas e } \\
\text { faces planas), bem unidos (bem aderidos entre si), } \\
\text { aparentemente sem porosidade entre torrões mas } \\
\text { com porosidade intra-agregados. Presença de raízes, } \\
\text { pouca porosidade biológica. Ds }=1,26( \pm 0,04) \mathrm{Mg} \\
\mathrm{m}^{-3} ; \text { Argila }=720 \mathrm{~g} \mathrm{~kg}^{-1}\end{array}$ \\
\hline OBS: & $\begin{array}{l}\text { - aparentemente, neste manejo sem rotação de } \\
\text { culturas as raízes e a atividade biológica encontraram } \\
\text { ambiente menos propício ao seu desenvolvimento }\end{array}$ \\
\hline
\end{tabular}

partículas do solo após a implantação do manejo, e do tráfego de grandes máquinas (tratores, semeadoras e colheitadeira) nas operações de plantio e colheita, muitas vezes em condições inadequadas (Silva et al., 2000a; Costa et al., 2003; Silva et al., 2005; Tavares Filho et al., 2010).

Os outros dois manejos, CASDE com boa cobertura de solo mas sem rotação de culturas, e CAPM, confirmaram que, quando revolvido, o solo tende a apresentar uma estrutura mais compacta $\left(\mathrm{C} \Delta\right.$ com Ds $>1,35 \mathrm{Mg} \mathrm{m}^{-3}$ de $\left.20-30 \mathrm{~cm}\right)$ entre a superfície e a base do trabalho do implemento utilizado (escarificador, arado ou grade). Este efeito ocorreu em menor escala no caso da escarificação quadrianual(eventual)feita no solo sob plantio direto de longo prazo.

Portanto, os manejos de solo conservacionistas, tal como a semeadura direta, com menor revolvimento e rotação de 
Tabela 4. Perfis de solos sob cultura anual com semeadura direta e escarificação de 4 em 4 anos, sem rotação de culturas (CASDE)

\begin{tabular}{|c|c|}
\hline $\begin{array}{c}\text { Modo de } \\
\text { organização } \\
\text { estrutural }\end{array}$ & Descrição feita a campo \\
\hline $\begin{array}{c}F \Delta \mu \\
(0-20 \mathrm{~cm})\end{array}$ & $\begin{array}{l}\text { Estrutura "com fissuras" fragmentada com torrões } \\
\text { predominantemente poliédricos angulares (arestas } \\
\text { angulares e faces planas e lisas) separados por } \\
\text { fissuras nítidas embora ainda tenha sido possível } \\
\text { visualizar presença de torrões com aspecto poroso, } \\
\text { porosidade predominante entre agregados (fissuras), } \\
\text { pouca porosidade intra-agregados, desenvolvimento } \\
\text { de raízes nas fissuras. Ds }=1,23( \pm 0,06) \mathrm{Mg} \mathrm{m}^{-3} \text {; } \\
\text { Argila }=600 \mathrm{~g} \mathrm{~kg}^{-1}\end{array}$ \\
\hline $\begin{array}{c}\mathrm{C} \Delta \\
(20-30 \mathrm{~cm})\end{array}$ & 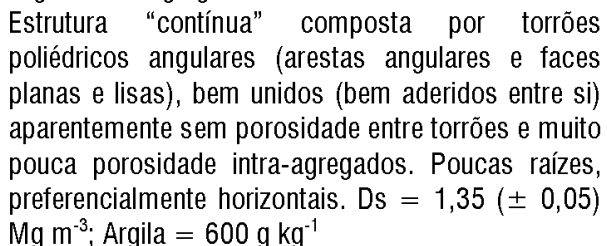 \\
\hline $\begin{array}{c}\mathrm{C} \mu \\
(30-50 \mathrm{~cm})\end{array}$ & $\begin{array}{l}\text { Estrutura "contínua" composta por torrões poliédricos } \\
\text { subangulares (arestas arredondadas e faces planas), } \\
\text { bem unidos (bem aderidos entre si) aparentemente } \\
\text { sem porosidade entre torrões mas com porosidade } \\
\text { intra-agregados. Presença de ráizes. Ds }=1,23 \text { ( } \pm \\
0,03 \text { ) } \mathrm{Mg} \mathrm{m}^{-3} \text {. Argila }=720 \mathrm{~g} \mathrm{~kg}^{-1}\end{array}$ \\
\hline OBS: & $\begin{array}{l}\text { - desenvolvimento radicular mais superficial; } \\
\text { ausência de porosidade biológica }\end{array}$ \\
\hline
\end{tabular}

Tabela 5. Perfis de solos sob cultura anual com preparo mínimo do solo, sem uso de rotação de culturas (CAPM)

\begin{tabular}{|c|c|}
\hline $\begin{array}{c}\text { Modo de } \\
\text { organização } \\
\text { estrutural }\end{array}$ & Descrição feita a campo \\
\hline $\begin{array}{c}F \mu \Delta \\
(0-20 \mathrm{~cm})\end{array}$ & $\begin{array}{l}\text { Estrutura "com fissuras" fragmentada, com torrões } \\
\text { predominantemente poliédricos subangulares } \\
\text { (arestas arredondadas e faces planas) separados por } \\
\text { fissuras nítidas embora também tenha sido possível } \\
\text { visualizar presença de torrões com aspecto } \\
\text { compacto, porosidade predominante entre agregados } \\
\text { (fissuras) com porosidade visível entre e intra- } \\
\text { agregados mas com desenvolvimento de raízes, } \\
\text { preferencialmente nas fissuras. Ds }=1,20( \pm 0,05) \\
\mathrm{Mg} \mathrm{m}^{-3} \text {; Argila }=500 \mathrm{~g} \mathrm{~kg}^{-1}\end{array}$ \\
\hline $\begin{array}{c}\mathrm{C} \Delta \\
(20-26 \mathrm{~cm})\end{array}$ & $\begin{array}{l}\text { Estrutura "contínua" composta por torrões } \\
\text { poliédricos angulares (arestas angulares e faces } \\
\text { planas e lisas), bem unidos (bem aderidos entre si) } \\
\text { aparentemente sem porosidade entre torrões e pouca } \\
\text { porosidade intra-agregados. Poucas raízes, essas } \\
\text { preferencialmente horizontais. Ds }=1,38( \pm 0,04) \\
\mathrm{Mg} \mathrm{m}^{-3} ; \text { Argila }=600 \mathrm{~g} \mathrm{~kg}^{-1}\end{array}$ \\
\hline $\begin{array}{c}\mathrm{C} \mu \\
(26-50 \mathrm{~cm})\end{array}$ & $\begin{array}{l}\text { Estrutura "contínua" composta por torrões } \\
\text { poliédricos subangulares (arestas arredondadas e } \\
\text { faces planas), bem unidos (bem aderidos entre si) } \\
\text { aparentemente sem porosidade visível entre torrões } \\
\text { mas com porosidade intra-agregados. Poucas raízes. } \\
\text { Ds }=1,25( \pm 0,06) \mathrm{Mg} \mathrm{m}^{-3} \text {; Argila }=720 \mathrm{~g} \mathrm{~kg}^{-1}\end{array}$ \\
\hline OBS: & $\begin{array}{l}\text { - desenvolvimento radicular mais superficial; } \\
\text { ausência de porosidade biológica }\end{array}$ \\
\hline
\end{tabular}

culturas (CASDR) mantêm, parcial ou totalmente, os resíduos vegetais na superfície e aportam continuamente matéria orgânica ao solo, a qual é responsável pela manutenção e melhoria das propriedades físicas do solo (Castro Filho et al., 1998) permitindo a consolidação do sistema sem que se formem camadas compactas contínuas.

Esta análise de perfis também mostrou que nenhuma limitação encontrada, mesmo nos casos mais extremos, representou um obstáculo que não pudesse ser corrigido com práticas vegetativas. Abaixo dos $30 \mathrm{~cm}$ todos os perfis analisados apresentavam condições satisfatórias, do ponto de vista morfológico.

Em relação aos resultados da resistência do solo à penetração, observa-se (Tabela 6) para valores de umidade gravimétrica relativamente próximos entre si, que a média dos valores de resistência é igual a 2,0 $\mathrm{MPa}$ (para o manejo CASDR) ou superior a $2 \mathrm{MPa}$ (para os demais manejos). Existe certa variação na bibliografia sobre quais valores de RP são restritivos ao crescimento de raízes das plantas cultivadas. O valor de $2 \mathrm{MPa}$,considerado por Taylor \& Gardner (1963) como impeditivo ao crescimento de raízes de algodão, passou a ser tradicionalmente utilizado como restritivo mas não impeditivo ao crescimento de raízes da maioria das culturas. Canarache (1990) sugeriu valores acima de 2,5 MPa como críticos em solos argilosos. Azooz et al. (1996) classificaram valores entre 2 e 4 MPa como altos e acima de $4 \mathrm{MPa}$ muito altos. Trabalhando com o mesmo tipo de solo do presente artigo, Tavares Filho et al. (2001) concluíram que valores de RP entre 2 e 4 MPa não foram impeditivos ao crescimento radicular de milho embora tenham mas provocado alterações morfológicas no solo e nas raízes.

Tabela 6. Valores médios e erro padrão da média da umidade gravimétrica $(\mathrm{Ug})$, da resistência do solo à penetração (RP) e do grau de floculação da argila (GF), para os diferentes usos e manejos do solo nas propriedades agrícolas estudadas

\begin{tabular}{clcl}
\hline Manejo* $^{*}$ & $\mathbf{U g}\left(\mathbf{k g ~ k g}^{-\mathbf{1}}\right)$ & $\mathbf{R P}(\mathbf{M P a})$ & $\mathbf{G F}(\%)$ \\
CASDR & $0,26 \pm 0,02$ & $\mathbf{0}-\mathbf{0 , 3 0} \mathbf{~}$ & \\
CASD & $0,26 \pm 0,01$ & $2,5 \pm 0,2$ & $86 \pm 2$ \\
CASDE & $0,24 \pm 0,02$ & $2,3 \pm 0,7$ & $82 \pm 3$ \\
CAPM & $0,22 \pm 0,02$ & $2,6 \pm 0,7$ & $79 \pm 5$ \\
\hline
\end{tabular}

Média de 4 repetições

* CASDR (cultura anual em semeadura direta com rotação de culturas); CASD (cultura anual em semeadura direta sem rotação de culturas); CASDE (cultura anual em semeadura direta sem rotação de culturas e escarificação quadrianual); CAPM (cultura anual em preparo mínimo, sem rotação de culturas)

Para o manejo CASDR, a RP máxima de 2,2 MPa (Tabela 6) valor relativamente baixo se for considerado um tráfego maior de máquinas devido a alternância de plantas de inverno e verão, mostra o quanto a rotação de culturas, com diferentes sistemas radiculares e incorporação de matéria orgânica ao solo, pode contribuir para minimizar os efeitos dos implementos causando menores índices de compactação do solo. Esses valores máximos analisados na ótica do perfil cultural apresentado anteriormente, mostram que em nenhum momento foi caracterizada compactação visível, em vista das estruturas de solo descritas ( $\mathrm{L} \mu$ - Estrutura Livre, com torrões porosos e $\mathrm{C} \mu$ - Estrutura Contínua, com torrões porosos) e da normalidade no desenvolvimento das raízes (sem achatamento e tortuosidade marcantes) enquanto o manjo CASD apresentou valores de resistência superiores ao manejo CASDR, ou seja, RP variou de 2,1 a 2,9 MPa. Esses valores mais altos de RP confirmaram 
a compactação detectada na análise do perfil cultural, em vista das estruturas de solo descritas ( $\mathrm{C} \Delta \mu$ - Estrutura Contínua, com torrões mais compactos que porosos) em superfície entre $0-20$ $\mathrm{cm}$ e raízes com desenvolvimento preferencialmente horizontal, com achatamento e tortuosidade marcantes. Este resultado está em acordo com Silva et al. (2000b); Fuentes-Llanillo et al. (2006b) os quais relatam que em sistemas de plantio direto os maiores valores de RP ocorrem em torno de $10 \mathrm{~cm}$, ou seja, superficialmente. Por outro lado e segundo Corsini \& Ferraudo (1999) essas restrições ao crescimento radicular com RP próximas de $3 \mathrm{MPa}$, caracterizam uma compactação no plantio direto de curto prazo nesse tipo de solo que, somente a partir do quinto ano agrícola, começa a se inverter, até que o sistema de PD atinja a consolidação, em torno do oitavo ano (Pereira Neto et al., 2007).

O manejo CASD com escarificação de 4 em 4 anos, sem rotação de culturas, apresentou RP superior ao manejo CASDR e inferior ao CASD, sendo que seus valores de RP variaram de 1,6 a 3,0 MPa. Esta importante variação de 1,4 MPa se deve, provavelmente, ao fato de que somente a partir do quinto ano agrícola o sistema de plantio direto começa a se estabilizar, segundo Corsini \& Ferraudo (1999). O efeito da escarificação constante do solo foi claramente percebido na descrição das estruturas do solo, no qual foi observada em superfície (0$20 \mathrm{~cm}$ ) uma estrutura $\mathrm{F} \Delta \mu$ (estrutura fissurada com torrões mais compactos que porosos e desenvolvimento de raízes preferencialmente entre as fissuras) seguida de uma estrutura $\mathrm{C} \Delta$ (estrutura contínua, com torrões compactos, raízes em menor número e tortuosas) que representa a base do revolvimento pelo implemento de preparo do solo e que se vai compactando pouco a pouco, com o passar dos anos, em função da maior movimentação pelo escarificador.

No caso do manejo CAPM sem rotação de culturas, foi detectado o maior valor médio de RP, 2,6 MPa; este elevado valor de resistência influiu nas estruturas do perfil cultural dessa área, ou seja, estrutura $F \mu \Delta$ (estrutura fissurada com torrões mais porosos que compactos) em superfície e $\mathrm{C} \Delta$ (Estrutura Contínua, com torrões compactos, raízes em número muito reduzido).

Levando-se em conta os resultados da Tabela 6, as referências bibliográficas já citadas e o trabalho de Fuentes-Llanillo (2007) em Latossolo Vermelho Distroférrico argiloso, considerou-se a faixa de RP entre 2 a 3 MPa como de transição entre condições adequadas e condições restritivas ao desenvolvimento radicular de culturas de grãos, consubstanciadas pela análise de perfis culturais de solo devendo-se dar especial atenção ao estudo da morfologia das estruturas do solo e das raízes (especialmente aspectos de "achatamento e tortuosidade") (Tavares Filho et al., 2001). Além disto, a presença de maiores RP em preparo mínimo de solo e em SD em curto prazo e de menores RP em SD com rotação de culturas em médio e longo prazo fortalece a ideia de um ciclo de maturidade para o plantio direto. Entre o quinto e oitavo anos, através principalmente do aumento da matéria orgânica e da atividade biológica na estrutura do solo, ocorre melhoria das condições físicas do solo, inclusive com diminuição dos valores de resistência à penetração (Corsini \& Ferraudo, 1999). Caso haja condições inadequadas de tráfego ou deficiências na construção de maiores níveis superficiais de matéria orgânica, este ciclo pode desvirtuar-se em compactação.
Com referência ao grau de floculação, observa-se (Tabela 6) que os valores médios obtidos variam de 75\% (manejo CAPM) a $86 \%$ (manejo CASDR) sendo o maior erro padrão da média para o manejo CAPM.Esses resultados estão em acordo com Castro Filho et al. (2002) e a provável explicação para esta diferença entre manejos no grau de floculação da argila pode residir em uma hipótese de natureza mecânica devido ao preparo do solo o qual pode aumentar a dispersão do solo e reduzir na mesma proporção o grau de floculação da argila (Tavares Filho \& Tessier, 1998; Tavares Filho et al., 2010).

Apresenta-se, a seguir, o diagrama comparativo dos manejos estudados (Figura 1) o qual constitui uma síntese dos aspectos abordados nos perfis culturais (descrição morfológica dos perfis), resistência à penetração e grau de floculação da argila. Observa-se no manejo CASDR que, segundo a descrição do perfil cultural, não apresentava ocorrência de compactação (Ds em torno de $1,20 \mathrm{Mg} \mathrm{m}^{-3}$ ) a RP foi igual ao valor de referência,o GF foi $14 \%$ menor que o valor de referência e a produção de soja (média de 6 anos) foi 13,3\% acima do valor de referência podendo, desta forma, ser qualificado como semeadura direta consolidada.

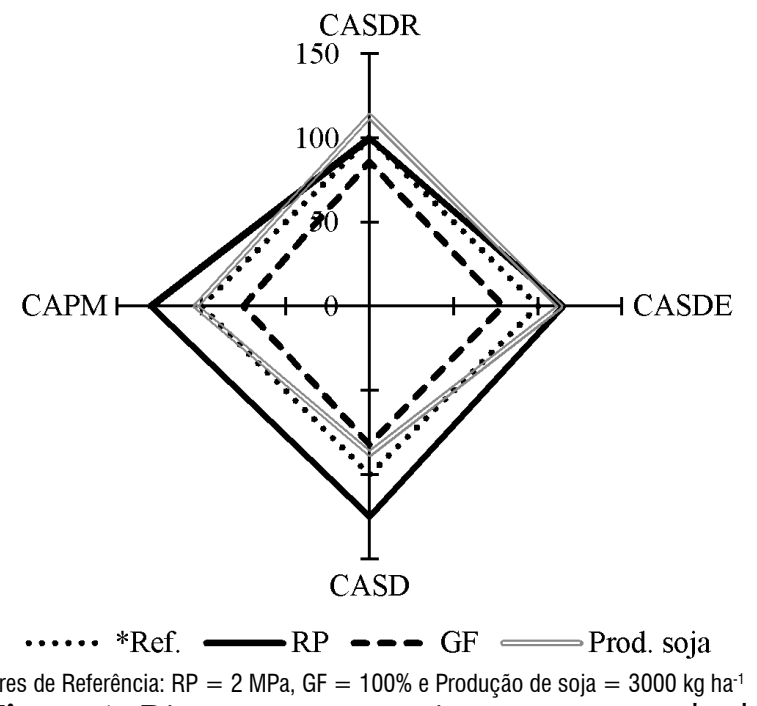

"Valores de Referência: $\mathrm{RP}=2 \mathrm{MPa}, \mathrm{GF}=100 \%$ e Produção de soja $=3000 \mathrm{~kg} \mathrm{ha}^{-1}$
Figura 1. Diagrama comparativo para a camada de solo de $0-0,30 \mathrm{~m}$ dos manejos estudados (CASDR - cultura anual em semeadura direta com rotação de culturas; CASDE - cultura anual em semeadura direta sem rotação de culturas e escarificação de 4 em 4 anos; CASD - cultura anual em semeadura direta sem rotação de culturas e CAPM-cultura anual em preparo mínimo) em relação à resistência a penetração $(\mathrm{RP})$ e grau de floculação da argila (GF)

Em relação ao manejo CASDE, o valor da RP (Figura 1) foi igual a 2,3 $\mathrm{MPa}$ ( $15 \%$ superior ao valor de referência),o GF foi $21 \%$ menor que o valor de referência e a produção de soja foi $13,0 \%$ acima do valor de referência. Portanto, a escarificação do solo de 4 em 4 anos propiciou um ambiente um pouco mais compacto e menos floculado que o manejo CASDR; entretanto, sem muita diferença em relação à produção de soja; já no manejo CASD, sem rotação de culturas, a RP foi igual a $2,5 \mathrm{MPa}$ ( $25 \%$ superior ao valor de referência),o GF foi $18 \%$ menor que o valor de referência e a produção de soja foi $12,5 \%$ 
menor que o valor de referência, indicando que a floculação do solo é devida, provavelmente, à compactação ao longo do período de uso do solo com máquinas pesadas e falta de rotação de culturas sendo que o solo não está mais apresentando as melhores condições para a produção de soja.

No sistema de manejo CAPM a RP foi iguala 2,6 $\mathrm{MPa}$ (30\% superior ao valor de referência), o GF foi $25 \%$ menor que o valor de referência e a produção de soja foi 3,3\% acima do valor de referência e 15,8\% superior ao sistema CASD sem rotação de culturas. Portanto, o trabalho constante do solo tende a aumentar a compactação, reduzir a floculação do solo, o que pode favorecer a erosão na área mas "cria condições melhores" para a produção de soja que o CASD e piores que os outros dois sistemas estudados, como mostrou a análise morfológica dos perfis. Os resultados levantados neste trabalho para o manejo CAPM indicam que este manejo foi bem executado.

\section{Conclusões}

1. Cada manejo estudado foi caracterizado por um tipo de estrutura de solo a qual se correlacionou com os valores de resistência, densidade e grau de floculação.

2. Em todos os manejos estudados abaixo dos $0,30 \mathrm{~m}$, os perfis analisados apresentavam condições estruturais satisfatórias ao desenvolvimento radicular.

\section{Agradecimentos}

Aos técnicos agrícolas Ronaldo Rossetto e Pedro Machado, do IAPAR, pelas leiturasde resistência à penetração, amostragens de densidade e umidade e pela amizade geral.Ao pesquisador cubano Angel Rosales Valdez, pela colaboração na realização dos perfis culturais e nas diversas amostragens no trabalho de campo. Às famílias Correia, Menotti, Migoto e Omura, pela disponibilidade de informações e colaboração na obtenção das referências técnicas que embasam este artigo. Ao Antônio Stefano Martin, pelo exímio trabalho de construção de trincheiras para observação científica dos perfis culturais.

\section{Literatura Citada}

Assouline, S.; Tavares Filho, J.; Tessier, D. Effect of compaction on soil physical properties: Experimental results and modeling. Soil Science Society of American Journal, v.61, p.391-398, 1997.

Azooz, R. H.; Arshad, M. A.; Franzlüebbers, A. J. Pore size distribution and hydraulic conductivity affected by tillage in northwestern Canada. Soil Science Society of American Journal,v.60, p.1197-1201, 1996.

Ball, B. C.; Batey, T.; Munkholm, L. J. Field assessment of soil structural quality: A development of Peerlkamp test. Soil Use and Management, v.23, p.329-337, 2007.

Ball, B. C.; Douglas, J. T. A simple procedure for assessing soil structural, rooting and surface conditions. Soil Use and Management.v.19, p.53-56, 2003.

Benito N. P.; Guimarães M. F.; Pasini, A. Caracterização de sistemas de manejo em Latossolo Vermelho utilizando parâmetros biológicos, físicos e químicos. Semina: Ciências Agrárias, v.29, p.473-484, 2008.
Bernoux, M.; Cerri, C. C.; Cerri, C. E. P.; Siqueira neto, M.; Metay, A.; Perrin, A.; Scopel, E.; Razafimbelo, T.; Blavet, D.; Piccolo, M. C.; Pavei, M.; Milne, E. Cropping systems, carbon sequestration and erosion in Brazil, a review. Agronomy for Sustainable Development, v.26, p.75-85, 2006.

Bolliger,A.; Magrid, J.; Amado,T. J. C.; Skóra Neto, F.; Ribeiro M. F. S.; Calegari A.; Neergard, A. de. Taking stock of the brazilian "zero-till revolution": A review of landmark research and farmers' practice. Advances in Agronomy, v.91, p.47-110, 2006.

Canarache, A. PENETR - A generalized semi-empirical model estimating soil resistance to penetration. Soil Tillage and Research, v.16, p.51-70, 1990.

Castro Filho, C.; Lourenço, A.; Guimarães, M. F.; Fonseca, I. C. B. Aggregate stability under different soil management systems in a red latosol in the state of Parana, Brazil. Soil Tillage and Research, v.65, p.45-51, 2002.

Castro Filho, C.; Muzilli, O.; Podanoschi, A. L. Estabilidade dos agregados e sua relação com o teor de carbono orgânico num Latossolo Roxo distrófico, em função de sistemas de plantio, rotações de culturas e métodos de preparo de amostras. Revista Brasileira de Ciência do Solo, v.22, p.527-538, 1998.

Corsini, P. C.; Ferraudo, A. S. Efeitos de sistemas de cultivo na densidade e na macro porosidade do solo e no desenvolvimento radicular do milho em Latossolo Roxo. Pesquisa Agropecuária Brasileira, v.34, p.289-298, 1999.

Costa, F. S.; Albuquerque, J. A.; Bayer, C.; Fontoura, S. M. V.; Wobeto, C. Propriedades físicas de um Latossolo Bruno afetadas pelos sistemas de plantio direto e preparo convencional. Revista Brasileira de Ciência do Solo, v.27, p.527-535, 2003.

EMBRAPA - Empresa Brasileira de Pesquisa Agropecuária. Manual de métodos de análise de solos. Rio de Janeiro: Embrapa CNCS. 1997. 212p.

Fuentes-Llanillo, R. Indicadores de sustentabilidade da produção familiar mecanizada de grãos em modalidades de plantio direto no Norte do Paraná, Brasil. Londrina: Universidade Estadual de Londrina, 2007. 129p. Tese Doutorado

Fuentes-Llanillo, R.; Grossi, M. E. del; Santos, F. O.; Munhos, P. D.; Guimarães, M. F. Regionalização da agricultura do estado do Paraná. Ciência Rural, v.36, p.121-127, 2006a.

Fuentes-Llanillo, R.; Richart, A.; Tavares Filho, J.; Guimarães, M. F.; Ferreira, R. R. M. Evolução de propriedades físicas do solo em função dos sistemas de manejo em culturas anuais. Semina: Ciências Agrárias, v.27, p.205-220. 2006 b.

Giarola, N. F. B.; Silva, A. P.; Tormena, C. A.; Ball, B.; Rosa, J. A. Visual soil structure quality assessment on Oxisols under no-tillage system. Scientia Agrícola, v.67, p.479-482, 2010.

Giarola, N. F. B.; Tormena, C. A.; Dutra, A. C. Degradação física de um Latossolo Vermelho utilizado para produção intensiva de forragem. Revista Brasileira de Ciência do Solo, v.31, p.863-873, 2007.

Hobbs, P. R. Conservation agriculture: What is it and why is it important for future sustainable food production? Journal of Agricultural Science, v.145, p.127-137, 2007.

Lal, R.; Stewart, B.A. Soil degradation: A global threat. Advances in Soil Science, v.11, p.13-17, 1990. 
McGarry, D. Soil compaction in long-term no-tillage. In: World Congress on Conservation Agriculture, 2, 2003, Foz do Iguaçu (PR), Brazil. Proceedings... Foz do Iguaçu: FEBRAPDP/CAAPAS, 2003.p.87-90.

Neves, C. S. V. J.; Feller, C.; Guimarães, M. F.; Medina, C. C.; Tavares Filho, J.; Fortier, M. Soil bulk density and porosity of homogeneous morphological units identified by the Cropping Profile Method in clayey Oxisols in Brazil. Soil Tillage and Research, v.71, p.109-119, 2003.

Pereira Neto, O. C.; Guimarães, M. F.; Ralisch R.; Fonseca, I. C. B. Análise do tempo de consolidação do sistema de plantio direto. Revista Brasileira de Engenharia Agrícola e Ambiental, v.32, p.115-125, 2007.

Reichert, J. M.; Reinert, D. J.; Braida, J. A. Qualidade dos solos e sustentabilidade de sistemas agrícolas. Ciência e Ambiente, v.27, p.29-48, 2003.

Silva, R. R.; Silva, M. L. N.; Ferreira, M. M. Atributos físicos indicadores da qualidade do solo sob sistemas de manejo na bacia do Alto do Rio Grande (MG). Ciência e Agrotecnologia, v.29, p.719-730, 2005.

Silva, V. R.; Reinert, D. J.; Reichert, J. M. Susceptibilidade à compactação de um Latossolo Vermelho-Escuro e de um Podzólico Vermelho-Amarelo. Revista Brasileira de Ciência do Solo, v.24, p.239-249, 2000a.

Silva, V. R.; Reinert, D. J.; Reichert, J. M. Resistência mecânica do solo à penetração influenciada pelo tráfego de uma colhedora em dois sistemas de manejo do solo. Ciência Rural, v.30, p.795-801, 2000 b.
Tavares Filho, J; Barbosa, G. M. C.; Guimarães, M. F.; Fonseca, I. C. B. Resistência do solo à penetração e desenvolvimento radicular do milho (Zea mays) sob diferentes sistemas de manejo em Latossolo Roxo. Revista Brasileira de Ciência do Solo, v.25, p.725-730, 2001.

Tavares Filho, J.; Barbosa, G. M. C.; Ribon, A. A. Physical properties of Dystrophic Red Latosol (Oxisol) under different agricultural uses.Revista Brasileira de Ciência do Solo, v.34, p.925-933, 2010.

Tavares Filho, J.; Ralisch, R.; Guimarães, M. F.; Medina, C. C.; Balbino, L. C.; Neves, C. S. V. J. Método do perfil cultural para avaliação do estado físico de solos em condições tropicais. Revista Brasileira de Ciência do Solo, v.23, p.393-399, 1999.

Tavares Filho, J.; Tessier, D. Influence des pratiques culturales sur le comportement et les propriétés de sols du Paraná (Brésil). Etude et Gestion des Sols, v.5, p.61-71, 1998.

Tavares Filho, J.; Tessier, D. Compressibility of oxisol aggregates under no-till in response to soil water potential. Revista Brasileira de Ciência do Solo, v.33, p.1525-1533, 2009.

Tavares Filho, J.; Tessier, D. Effects of different management systems on porosity of oxisols in Paraná, Brazil. Revista Brasileira de Ciência do Solo, v.34, p.899-906, 2010.

Taylor, H. M.; Gardner, H. R. Penetration of cotton seedlings taproots as influenced by bulk density, moisture and strength of soil. Soil Science, v.96, p.153-156, 1963. 